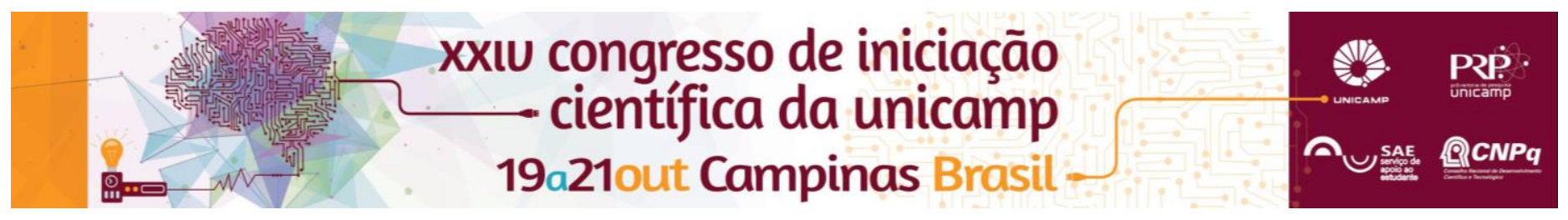

\title{
Digitalização de Imagem para Determinação de Capsaicinóides em Pimentas do Gênero Capsicum
}

\section{Fernanda Stangherlin Sartoratto*, Adriana Vitorino Rossi}

\section{Resumo}

Desenvolvimento de um método para quantificar capsaicinóides, compostos responsáveis pela ardência das pimentas do gênero Capsicum, a partir da digitalização de imagens de pimentas em diferentes estágios de maturação, a fim de estabelecer uma relação entre a concentração de capsaicinóides e a intensidade de cores RGB das imagens digitais.

\section{Palavras-chave:}

Capsaicinóides, Capsicum, RGB

\section{Introdução}

Capsaicinóides (CAPS) são alcaloides encontrados em pimentas do gênero Capsicum e são responsáveis pela ardência das mesmas. A sua determinação é importante, pois estes compostos vêm ganhando cada vez mais espaço no mercado. Pimentas desse gênero possuem uma grande quantidade de fibras, vitaminas e minerais, além de apresentarem propriedades que Ihes atribuem diversos efeitos medicinais, principalmente devido à presença de CAPS em sua constituição ${ }^{1}$.

Pretendeu-se desenvolver um método para quantificar CAPS a partir da digitalização de imagens de pimentas, a fim de estabelecer uma relação entre a concentração de CAPS e a intensidade de cores RGB (Red, Green, Blue) de imagens digitais das pimentas em diferentes estágios de maturação. $O$ estabelecimento do método com análise digital de imagens pode servir para obtenção de resultados úteis para orientar a colheita das pimentas no estágio de maturação mais adequado, no que diz respeito ao teor de CAPS.

Foram estudadas pimenta Dedo-de-Moça (Capsicum baccatum) e pimentas nucleares, com ardência acima de $800.00 \mathrm{SHU}$ (unidades Scoville). Para validar o método, foram realizadas comparações de resultados obtidos com dados espectrofotométricos, utilizando dihidrocapsaicina (DHCAP) como padrão analítico.

\section{Resultados e Discussão}

A primeira etapa do projeto envolveu testes estatísticos para verificar a representatividade da amostragem. Para isso foram preparados extratos de pimentas Dedo-deMoça, a partir de diferentes quantidades de pimentas, a fim de avaliar e utilizar o mínimo de amostra e tempo possível. As concentrações dos extratos foram obtidas por método espectrofotométrico, com medidas em triplicadas e aparecem na Tabela 1. Também foram realizados testes para verificar a influência do número de pontos das imagens digitais a serem considerados na coleta de intensidades de cores RGB.

Tabela 1. Quantidade de pimenta utilizada para preparo dos extratos e suas respectivas concentrações.

\begin{tabular}{|c|c|c|}
\hline Extratos & $\begin{array}{c}\text { Quantidade de } \\
\text { Pimentas (unidade) }\end{array}$ & $\begin{array}{c}\text { Concentração } \\
\left(\text { mol. }^{-1} \text { ) }\right.\end{array}$ \\
\hline 1 & 1 & $6,51 \times 10^{-4}$ \\
\hline 2 & 2 & $6,80 \times 10^{-4}$ \\
\hline 3 & 5 & $5,16 \times 10^{-4}$ \\
\hline 4 & 10 & $4,91 \times 10^{-4}$ \\
\hline 5 & 20 & $5,39 \times 10^{-4}$ \\
\hline
\end{tabular}

DOI: 10.19146/pibic-2016-50910
Os testes indicaram que os valores médios das componentes RGB da imagem de uma pimenta são iguais estatisticamente aos valores médios obtidos com 2, 10 e 20 pimentas. Além disso, os dados obtidos a partir de dados convertidos usando de 2 a 9 pontos das imagens são iguais estatisticamente para todas as componentes de cores.

Estudos realizados com as pimentas Dedo-de-Moça e as pimentas nucleares, em diferentes estágios de maturação, confirmaram a tendência de aumento da picância com o amadurecimento do fruto até certo ponto. É esperado que a partir de determinado estágio de maturação comecem a ocorrer processos que podem leva à degradação de CAPS. A correlação entre a concentração de CAPS e a intensidade de cores RGB com dados de pimenta Dedo-de-Moça em calibração multivariada linear forneceu resultados lineares. Foram utilizados dados de medidas em triplicatas, de pimentas em quatro estágios de maturação diferentes, ajustados pela equação abaixo, com coeficiente de correlação linear $=1$.

Concentração $=2,53 \times 10^{-7} \mathbf{R}-1,81 \times 10^{-6} \mathbf{G}+4,90 \times 10^{-5} \mathbf{B}+2,65 \times 10^{-5}$

\section{Conclusões}

Testes estatísticos indicaram que alterar a quantidade de pimentas utilizadas para o preparo do extrato de Dedode-Moça, de 1 a 20 pimentas, ou alterar a quantidade de pontos amostrados, de 2 a 9 pontos, para a obtenção de dados RGB, não afeta os resultados. Portanto, é possível obter os dados com a imagem de uma única pimenta, utilizando apenas 2 pontos, com grandes vantagens na redução do tempo para processamento de dados, o que aumento a frequência analítica.

Uma calibração multivariada linear mostrou uma forte correlação entre a intensidade de cores RGB com a concentração de CAPS presentes em pimentas Dedo-deMoça em diferentes estágios de maturação.

\section{Agradecimentos}

Ao $\mathrm{CNPq}$ - Conselho Nacional de Desenvolvimento Científico e Tecnológico por financiar o projeto, aos membros do GPQUAE - Grupo de Pesquisas em Química Analítica e Educação pelo apoio e infraestrutura e a Fábio Tuma pelo fornecimento das pimentas.

${ }^{1}$ Reifschneider, F. J. B.; Nass, L.L.; Heinrich, A. C.; Ribeiro, C. S. C.; Henz, G. P.; Filho, K. E.; Boiteux, L. S.; Ritschel, P.; Quecini, V.; "Uma pitada de biodiversidade na mesa do brasileiro"; Brasília; 2014. 